\title{
Meta-analysis of the association between aldose reductase gene (CA)n microsatellite variants and risk of diabetic retinopathy
}

\author{
WENSHENG MI ${ }^{1,2}$, YAN XIA ${ }^{1,2}$ and YANHUI BIAN ${ }^{1,2}$ \\ ${ }^{1}$ Department of Pathophysiology, School of Basic Medical Science, \\ Changsha Medical University; ${ }^{2}$ Department of Human Anatomy, Histology and Embryology, \\ Institute of Neuroscience, Changsha Medical University, Changsha, Hunan 410219, P.R. China
}

Received February 23, 2019; Accepted August 20, 2019

DOI: $10.3892 /$ etm.2019.8086

\begin{abstract}
Diabetic retinopathy (DR) is one of the most severe microvascular complications of diabetes mellitus (DM). The (CA)n microsatellite variation of the aldose reductase (ALR) gene has been indicated to be associated with DR in previous studies; however, the results were inconclusive. To provide a more precise evaluation of the association between the (CA)n variations of ALR and the risk for DR, a meta-analysis was performed in the present study. Relevant articles were retrieved from the PubMed, Embase, Chinese National Knowledge Infrastructure and Cochrane Library databases. Pooled odds ratios (ORs) and 95\% confidence intervals (CIs) were used to evaluate the strength of the associations. The present meta-analysis included 17 studies comprising 1,575 DM patients with retinopathy and 1,741 DM patients without retinopathy. The results indicated that the Z-2 allele was a risk factor for $\mathrm{DR}$ in Asian $(\mathrm{OR}=1.82,95 \% \mathrm{CI}$ : 1.16-2.86, $\mathrm{P}=0.009)$ and Caucasian $(\mathrm{OR}=2.08,95 \% \mathrm{CI}: 1.14-3.79, \mathrm{P}=0.02)$ populations, as well as in type 1 diabetes (T1D; OR=3.42, 95\% CI: 1.46-8.04, $\mathrm{P}=0.005)$ and type 2 diabetes (T2D; $\mathrm{OR}=1.66,95 \%$ CI: $1.05-2.63, \mathrm{P}=0.03)$. Furthermore, the $\mathrm{Z}+2$ allele was determined to be a protective factor for DR in Caucasian individuals $(\mathrm{OR}=0.50,95 \% \mathrm{CI}: 0.34-0.73, \mathrm{P}=0.0004)$ and those with T1D $(\mathrm{OR}=0.39,95 \% \mathrm{CI}: 0.27-0.57, \mathrm{P}<0.00001) . \mathrm{Z}+4$ was also identified to be a protective factor, reducing the risk of DR in patients with T1D (OR=0.74, 95\% CI: 0.57-0.96, P=0.02). Z-4 was revealed to be a risk factor for DR in Asian populations $(\mathrm{OR}=1.57,95 \% \mathrm{CI}: 1.22-2.03, \mathrm{P}=0.0005)$ and in individuals with T1D (OR=1.62, 95\% CI: 1.27-2.08, $\mathrm{P}=0.0001)$. However, no association was detected between the $\mathrm{Z}, \mathrm{Z}+6$ and $\mathrm{Z}-6$ alleles and the risk of DR $(\mathrm{P}>0.05)$. In conclusion, the present results
\end{abstract}

Correspondence to: Professor Yan Xia, Department of Pathophysiology, School of Basic Medical Science, Changsha Medical University, 1501 Leifeng Road, Changsha, Hunan 410219, P.R. China

E-mail: xiayancsmu518@sina.com

Key words: aldose reductase, diabetic retinopathy, variation, meta-analysis revealed the following: $Z+2$ may serve as a protective factor for DR in Caucasian individuals and those with T1D; Z+4 may be a protective factor for DR in patients with T2D; Z-2 may represent a risk factor for DR in all subgroups analyzed; and Z-4 may be a risk factor for DR in Asian populations and patients with T2D.

\section{Introduction}

Diabetic retinopathy (DR) is one of the major microvascular complications of diabetes mellitus (DM), including type 1 diabetes (T1D) and type 2 diabetes (T2D). It is one of the leading causes of blindness in patients with DM worldwide, particularly in industrialized countries $(1,2)$. In addition to hypertension and the duration of diabetes, chronic hyperglycaemia has been considered to be the major risk factor for the development of microvascular complications in patients with diabetes (3). Pedigree studies have indicated the presence of genetic influences in the development of these complications (4,5). Recently, genome-wide linkage analyses have begun to identify possible genetic associations with DR. A number of candidate genes have been investigated, including vascular endothelial growth factor (6), monocyte chemoattractant protein-1 (7), vitamin D receptor (8), aldehyde dehydrogenease 2 (9) and aldose reductase [ALR; also known as aldoketo reductase family 1, member B1 (ALDR1)] $(10,11)$.

ALR is the first and rate-limiting enzyme in the human polyol pathway, which occurs under hyperglycemic conditions (12). Excessive flux of glucose via the polyol pathway has been implicated in the pathogenesis of diabetic microvascular complications (13). The ALR gene, located on chromosome $7 \mathrm{q} 35$, extends over $\sim 18 \mathrm{~kb}$ and consists of 10 exons that give rise to a 1,384-nucleotide mRNA sequence, which encodes a 316 -amino-acid protein of 35,858 Da (14). It has been reported as a candidate locus for diabetic nephropathy $(15,16)$. Previous candidate-gene studies and meta-analyses have examined the hypothesis that two common ALR gene variants, including $106 \mathrm{C} / \mathrm{T}$ and $(\mathrm{CA}) \mathrm{n}$, are associated with the risk of DR (17-20). (CA)n is a microsatellite variant located $2.1 \mathrm{~kb}$ upstream of the ALR transcription initiation site that has been intensively studied. It has been demonstrated that (CA)n may cause increased enzyme levels or activity, thus contributing to diabetic nephropathy and DR (21-23). The Z-2 allele of the 
(CA)n ALR variant was determined to be associated with DR in Caucasian patients with T1D (24), in Chinese patients with T2D (25) and in Tunisian individuals (26). However, negative results were also reported in populations from Brazil (27) and Korea (28). For the Z+2 allele, significant associations were detected in Chinese (29), Tunisian (26) and Australian (24) populations, but not in Korean (28), Caucasian (30) and Brazilian (27) individuals.

Considering the relatively small sample size in individual studies and controversial results among others, the present study aimed to provide a more accurate evaluation of the association between (CA)n ALR variants and the risk of DR. A meta-analysis was performed to assess the association between ALR (CA)n variation (Z, Z-2/Z+2, Z-4/Z+4, Z-6/Z+6) and the susceptibility to DR.

\section{Materials and methods}

Search strategy. The meta-analysis of the present study followed the Cochrane collaboration definition (31) and PRISMA 2009 guidelines for meta-analyses and systematic reviews (32). A literature search was performed using the PubMed, Embase, Chinese National Knowledge Infrastructure (CNKI) and Cochrane Library databases. Studies investigating associations between ALR (CA)n variations and the risk for DR were identified using the following keywords: 'aldose reductase', 'ALR', 'ALDR1', 'ADR', 'AR', 'aldoketo reductase family 1', 'AKR1B1', 'polymorphism', 'variant', 'diabetic retinopathy' and 'DR'. No language restriction was applied. The search included articles published until August 10, 2018. Additional eligible studies were retrieved manually.

Studies were included if the following applied: i) A case-control design that included diabetes with retinopathy and diabetes without retinopathy, separately; ii) adequate data to calculate odds ratios (ORs) and 95\% confidence intervals (CIs); iii) evaluation of the association between ALR (CA)n variation and DR risk.

The following exclusion criteria were applied: Studies were excluded if they: i) Did not include the genetic association of ALR (CA)n variation and risk of DR; ii) were duplicates of studies, or letters, dissertations, abstracts or reviews; iii) lacked sufficient data for the determination of genotype frequencies.

Data extraction and quality assessment. The following terms were extracted from each eligible study: First author, year, age, percentage of males, disease duration, glycated hemoglobin, type of DM (T1D or T2D), number of patients with diabetes with retinopathy or without retinopathy. Two authors (YX and YB) independently extracted the above information. Any disagreement was resolved by discussion. The quality of each study was assessed by using the Newcastle-Ottawa Scale (NOS) (33). The NOS uses a 'star' rating system to judge the quality. The total score ranged from 0 (lowest quality) to 8 (highest quality). Studies with a score of $\geq 6$ were considered as being of high quality.

Statistical analysis. Statistical analyses were performed using STATA 12.0 software (StataCorp) and Revman 5 (Cochrane Collaboration). ORs with $95 \%$ CIs were used to assess the strength of associations between the allelic model

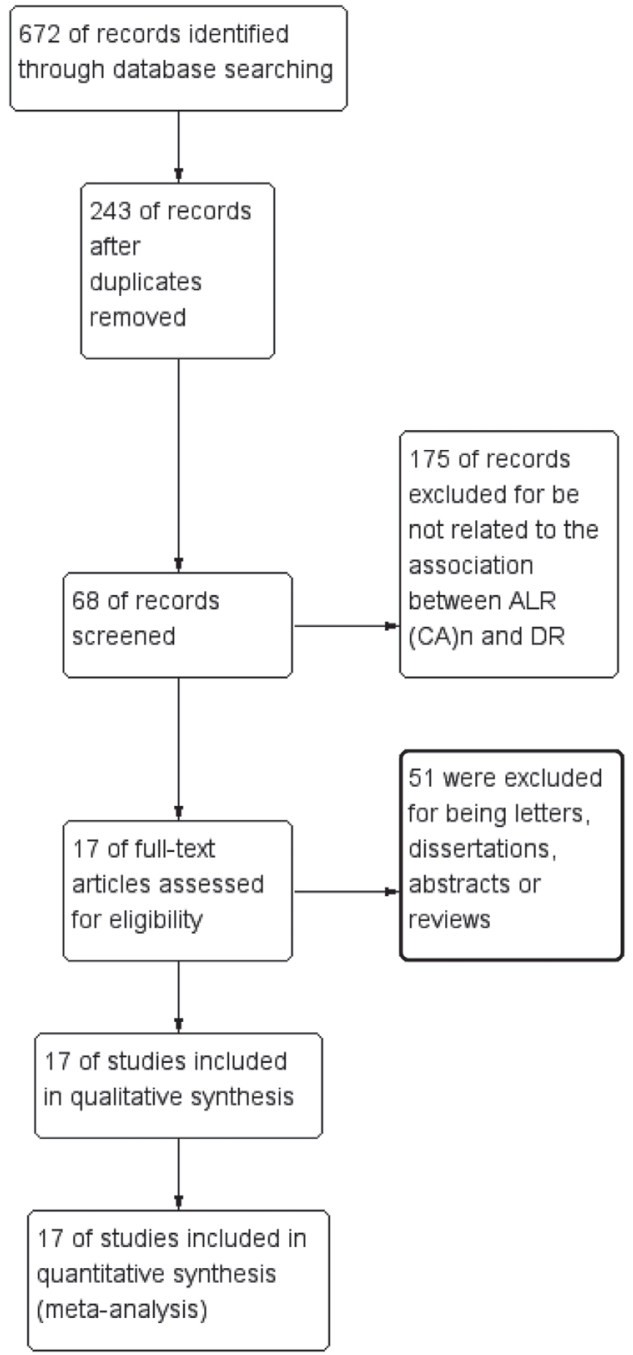

Figure 1. PRISMA flow chart of study inclusion and exclusion. DR, diabetic retinopathy; ALR, aldose reductase.

of (CA)n variation and the risk of DR. A Z-test was used to determine the pooled ORs. The heterogeneity among studies was evaluated by Cochrane's Q-statistic and $\mathrm{I}^{2}$ statistics. A random-effects model was used in case of significant heterogeneity $\left(\mathrm{I}^{2}>50 \%\right.$, or $\left.\mathrm{P}<0.05\right)$. Otherwise, the fixed-effects model was used. Sensitivity analyses were also performed using the fixed-effects model or random-effects model. A funnel plot in addition to an Egger's and Begg's test was used to assess potential publication bias. $\mathrm{P}<0.05$ was considered to indicate statistically significant differences.

\section{Results}

Characteristics of the published studies. As presented in Fig. 1, 672 articles met the inclusion criteria and the full articles were retrieved from the PubMed, Embase, CNKI and Cochrane Library databases after the initial search. A total of 243 publications were excluded due to being duplicates. After screening the titles and abstracts, 175 publications were excluded for not documenting the association between ALR (CA)n and DR. In addition, 51 studies were excluded for being letters, dissertations, abstracts or reviews. Finally, 17 articles were included in the present meta-analysis (24-30,34-43). The characteristics 


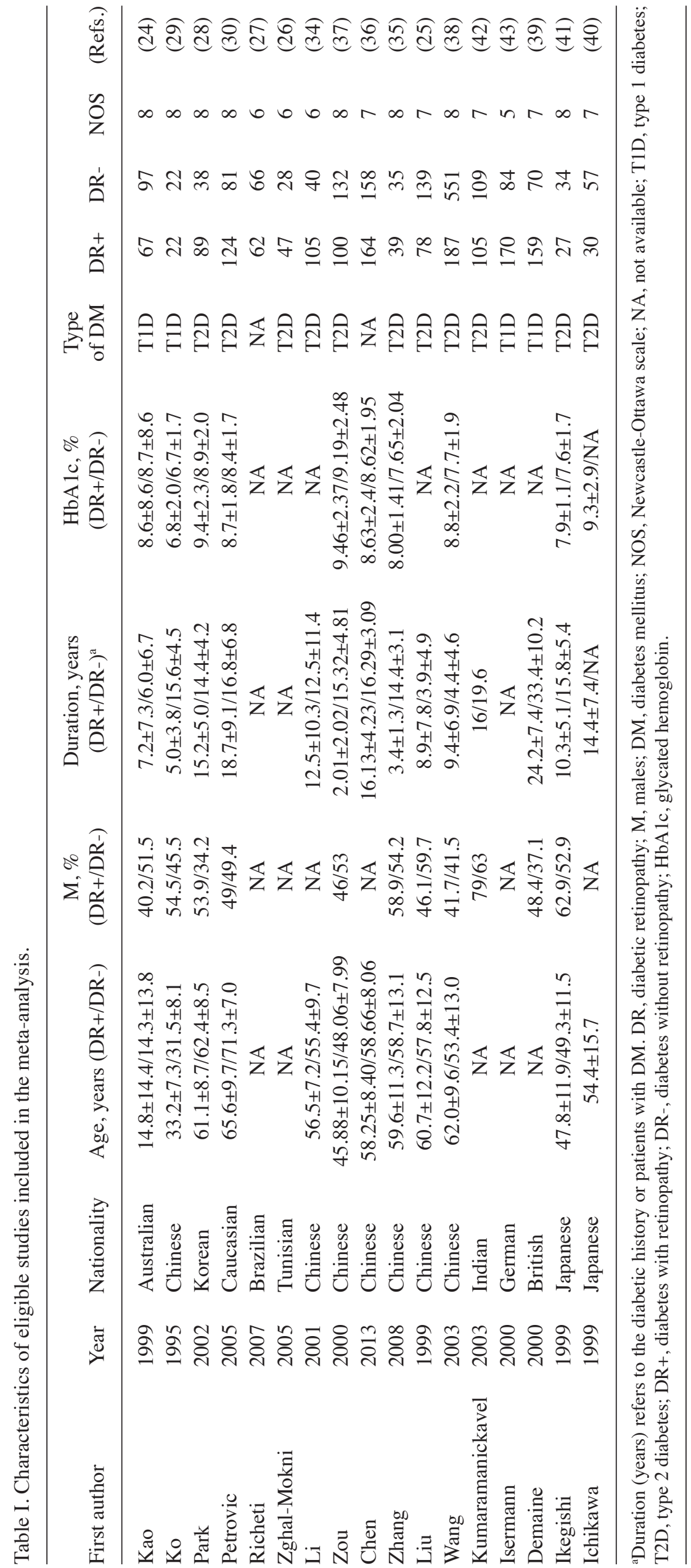


Table II. Pooled ORs and 95\% CIs of the association between (CA)n of aldose reductase gene and diabetic retinopathy.

\begin{tabular}{|c|c|c|c|c|c|c|c|c|}
\hline \multirow[b]{2}{*}{ Allele/subgroup } & \multirow[b]{2}{*}{ Number of studies } & \multicolumn{2}{|c|}{ Numbers } & \multicolumn{2}{|c|}{ Test of association } & \multirow[b]{2}{*}{ Model } & \multicolumn{2}{|c|}{$\begin{array}{c}\text { Test of } \\
\text { heterogeneity }\end{array}$} \\
\hline & & Cases & Controls & OR $(95 \% \mathrm{CI})$ & P-value & & P-value & $\mathrm{I}^{2}(\%)$ \\
\hline \multicolumn{9}{|l|}{$\mathrm{Z}$} \\
\hline Total & 16 & 2,822 & 3,166 & $0.95(0.84,1.08)$ & 0.42 & $\mathrm{~F}$ & 0.27 & 16 \\
\hline Asian & 11 & 1,658 & 2,370 & $1.00(0.86,1.16)$ & 0.98 & $\mathrm{~F}$ & 0.38 & 6 \\
\hline Caucasian & 5 & 1,164 & 796 & $0.86(0.69,1.06)$ & 0.16 & $\mathrm{~F}$ & 0.21 & 32 \\
\hline T1D & 4 & 836 & 546 & $0.88(0.67,1.15)$ & 0.34 & $\mathrm{~F}$ & 0.56 & 0 \\
\hline $\mathrm{T} 2 \mathrm{D}$ & 11 & 1,862 & 2,488 & $0.95(0.83,1.10)$ & 0.51 & $\mathrm{~F}$ & 0.71 & 29 \\
\hline \multicolumn{9}{|l|}{$\mathrm{Z}+2$} \\
\hline Total & 17 & 3,150 & 3,482 & $0.65(0.49,0.88)$ & 0.004 & $\mathrm{R}$ & $<0.00001$ & 75 \\
\hline Asian & 12 & 1,986 & 2,686 & $0.73(0.52,1.02)$ & 0.07 & $\mathrm{R}$ & $<0.00001$ & 75 \\
\hline Caucasian & 5 & 1,164 & 796 & $0.50(0.34,0.73)$ & 0.0004 & $\mathrm{~F}$ & 0.17 & 38 \\
\hline T1D & 4 & 836 & 546 & $0.39(0.27,0.57)$ & $<0.00001$ & $\mathrm{~F}$ & 0.32 & 14 \\
\hline $\mathrm{T} 2 \mathrm{D}$ & 11 & 1,862 & 2,488 & $0.82(0.60,1.12)$ & 0.22 & $\mathrm{R}$ & 0.0009 & 66 \\
\hline \multicolumn{9}{|l|}{ Z-2 } \\
\hline Total & 17 & 3,150 & 3,482 & $1.90(1.33,2.71)$ & 0.0004 & $\mathrm{R}$ & $<0.00001$ & 84 \\
\hline Asian & 12 & 1,986 & 2,686 & $1.82(1.16,2.86)$ & 0.009 & $\mathrm{R}$ & $<0.00001$ & 83 \\
\hline Caucasian & 5 & 1,164 & 796 & $2.08(1.14,3.79)$ & 0.02 & $\mathrm{R}$ & $<0.0001$ & 86 \\
\hline T1D & 4 & 836 & 546 & $3.42(1.46,8.04)$ & 0.005 & $\mathrm{R}$ & $<0.0001$ & 87 \\
\hline $\mathrm{T} 2 \mathrm{D}$ & 11 & 1,862 & 2,488 & $1.66(1.05,2.63)$ & 0.03 & $\mathrm{R}$ & $<0.00001$ & 93 \\
\hline \multicolumn{9}{|l|}{$\mathrm{Z}+4$} \\
\hline Total & 13 & 2,534 & 2,802 & $0.77(0.61,0.97)$ & 0.03 & $\mathrm{~F}$ & 0.58 & 0 \\
\hline Asian & 9 & 1,504 & 2,200 & $0.81(0.62,1.05)$ & 0.11 & $\mathrm{~F}$ & 0.53 & 0 \\
\hline Caucasian & 4 & 1,030 & 602 & $0.61(0.35,1.06)$ & 0.08 & $\mathrm{~F}$ & 48 & 0 \\
\hline T1D & 3 & 702 & 352 & $1.09(0.54,2.21)$ & 0.80 & $\mathrm{R}$ & 13 & 51 \\
\hline $\mathrm{T} 2 \mathrm{D}$ & 9 & 1,708 & 2,318 & $0.74(0.57,0.96)$ & 0.02 & $\mathrm{~F}$ & 0.65 & 0 \\
\hline \multicolumn{9}{|l|}{ Z-4 } \\
\hline Total & 14 & 2,594 & 2,916 & $1.57(1.25,1.98)$ & 0.0001 & $\mathrm{R}$ & 0.0003 & 66 \\
\hline Asian & 10 & 1,564 & 2,314 & $1.57(1.22,2.03)$ & 0.0005 & $\mathrm{R}$ & $<0.0001$ & 76 \\
\hline Caucasian & 4 & 1,030 & 602 & $1.57(0.94,2.62)$ & 0.09 & $\mathrm{~F}$ & 0.84 & 0 \\
\hline T1D & 3 & 702 & 352 & $1.29(0.66,2.53)$ & 0.45 & $\mathrm{R}$ & 0.13 & 50 \\
\hline $\mathrm{T} 2 \mathrm{D}$ & 11 & 1,768 & 2,432 & $1.62(1.27,2.08)$ & 0.0001 & $\mathrm{R}$ & 0.0001 & 73 \\
\hline \multicolumn{9}{|l|}{$\mathrm{Z}+6$} \\
\hline Total & 12 & 2,446 & 2,876 & $0.77(0.56,1.07)$ & 0.12 & $\mathrm{~F}$ & 0.29 & 15 \\
\hline Asian & 7 & 1,282 & 2,080 & $0.85(0.59,1.23)$ & 0.39 & $\mathrm{~F}$ & 0.11 & 42 \\
\hline Caucasian & 5 & 1,164 & 796 & $0.54(0.26,1.09)$ & 0.08 & $\mathrm{~F}$ & 0.85 & 0 \\
\hline T1D & 3 & 792 & 502 & $0.52(0.23,1.16)$ & 0.11 & $\mathrm{~F}$ & 0.51 & 0 \\
\hline $\mathrm{T} 2 \mathrm{D}$ & 8 & 1,530 & 2,242 & $0.85(0.59,1.21)$ & 0.36 & $\mathrm{~F}$ & 0.16 & 33 \\
\hline \multicolumn{9}{|l|}{ Z-6 } \\
\hline Total & 12 & 2,132 & 2,060 & $1.01(0.63,1.60)$ & 0.98 & $\mathrm{~F}$ & 0.52 & 0 \\
\hline Asian & 7 & 968 & 1,092 & $1.02(0.56,1.85)$ & 0.96 & $\mathrm{~F}$ & 0.38 & 6 \\
\hline Caucasian & 5 & 1,164 & 968 & $0.99(0.48,2.06)$ & 0.98 & $\mathrm{~F}$ & 0.44 & 0 \\
\hline T1D & 3 & 792 & 674 & $0.71(0.27,1.85)$ & 0.48 & $\mathrm{~F}$ & 0.28 & 22 \\
\hline $\mathrm{T} 2 \mathrm{D}$ & 8 & 1,216 & 1,254 & $1.12(0.65,1.93)$ & 0.67 & $\mathrm{~F}$ & 0.45 & 0 \\
\hline
\end{tabular}

F, fixed-effects model; R, random-effects model; OR, odds ratio; CI, confidence interval; T1D, type 1 diabetes; T2D, type 2 diabetes.

of all studies included are summarized in Tables I and SI. The NOS scores of all eligible studies ranged from 6 to 8 stars, indicating high methodological quality of all of the studies.
Among them, 12 studies were performed with Asian populations $(25,26,28,29,34-38,40-42)$ and 5 studies were performed with Caucasian populations $(24,27,30,39,43)$. Furthermore, 


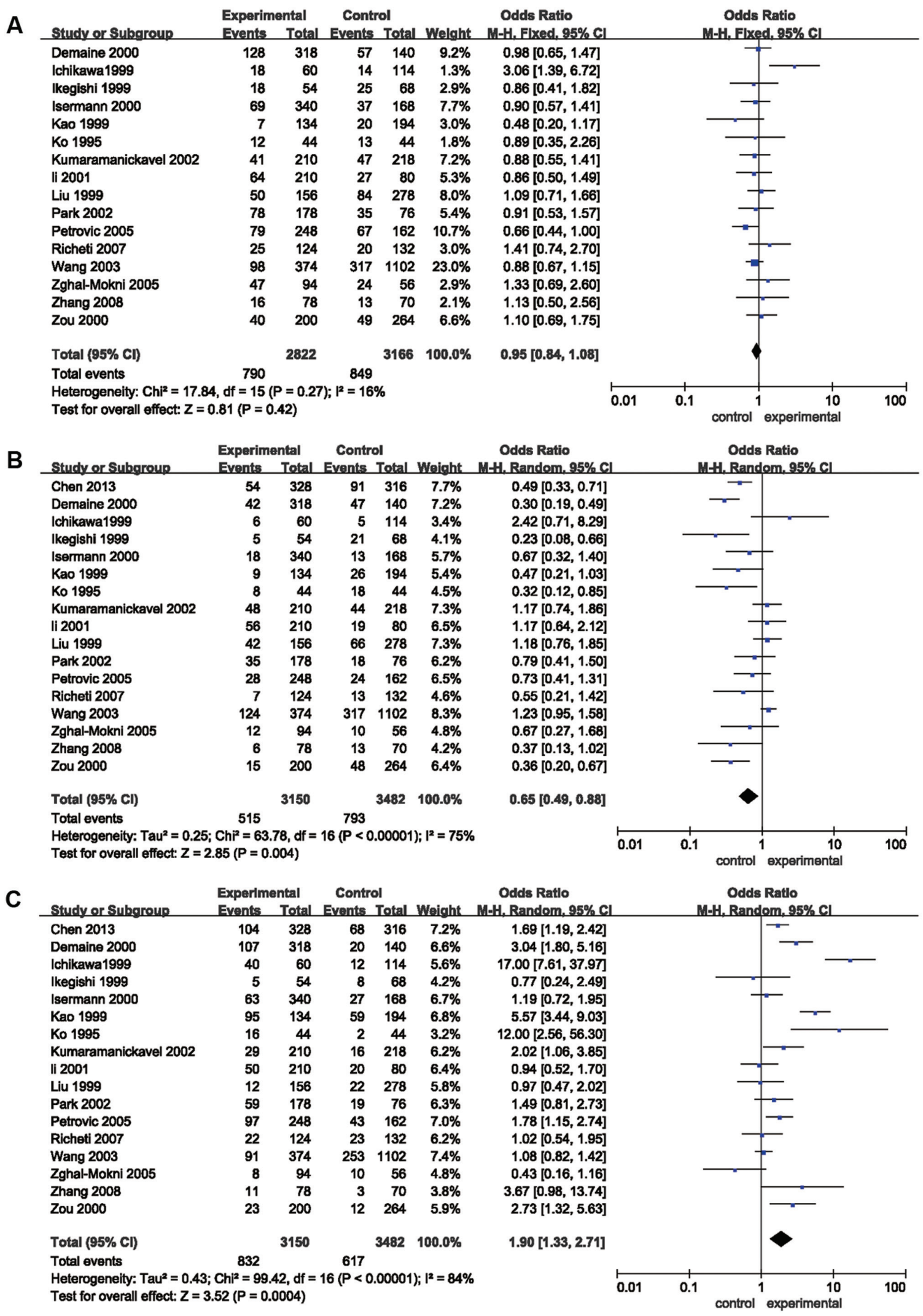

Figure 2. Forest plots of odds ratios for the association between aldose reductase (CA)n and the risk of diabetic retinopathy. (A) Z; (B) Z+2; (C) Z-2. M-H, Mantel-Haentzel; df, degrees of freedom.

4 articles included patients with T1D $(24,29,39,43)$ and 11 studies included patients with T2D $(25,26,28,30,34,35$, $37,38,40-42)$. The type of DM of the subjects in 2 remaining articles was not specified $(27,36)$.
Results of the meta-analysis. The results of the meta-analysis preformed in the present study are provided in Table II and Figs. 2 and 3. The pooled risk estimates indicated that the $\mathrm{Z}+2$ allele was associated with a decreased risk of $\mathrm{DR}(\mathrm{OR}=0.65,95 \%$ 


\begin{tabular}{|c|c|c|c|c|c|c|}
\hline ar Suhrino & Experim & intal & Contr & & & Odds Ratio \\
\hline 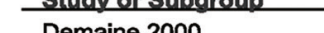 & & & & & & \\
\hline Demaine 2000 & 13 & 318 & 9 & 140 & $7.5 \%$ & $0.62[0.26,1.49]$ \\
\hline Ikegishi 1999 & 1 & 54 & 1 & 68 & $0.5 \%$ & $1.26[0.08,20.69]$ \\
\hline Isermann 2000 & 7 & 340 & 2 & 168 & $1.6 \%$ & $1.74[0.36,8.49]$ \\
\hline Ko 1995 & 4 & 44 & 0 & 44 & $0.3 \%$ & $9.89[0.52,189.43]$ \\
\hline Kumaramanickavel 2002 & 23 & 210 & 35 & 218 & $19.1 \%$ & $0.64[0.37,1.13]$ \\
\hline li 2001 & 21 & 210 & 7 & 80 & $5.7 \%$ & $1.16[0.47,2.84]$ \\
\hline Liu 1999 & 27 & 156 & 56 & 278 & $20.8 \%$ & $0.83[0.50,1.38]$ \\
\hline Park 2002 & 2 & 178 & 2 & 76 & $1.7 \%$ & $0.42[0.06,3.04]$ \\
\hline Petrovic 2005 & 7 & 248 & 11 & 162 & $8.1 \%$ & $0.40[0.15,1.05]$ \\
\hline Richeti 2007 & 2 & 124 & 4 & 132 & $2.4 \%$ & $0.52[0.09,2.92]$ \\
\hline Wang 2003 & 17 & 374 & 80 & 1102 & $24.2 \%$ & $0.61[0.36,1.04$ \\
\hline Zhang 2008 & 3 & 78 & 3 & 70 & $1.9 \%$ & $0.89[0.17,4.5$ \\
\hline Zou 2000 & 12 & 200 & 12 & 264 & $6.1 \%$ & $1.34[0.59,3.05]$ \\
\hline Total (95\% C & & 2534 & & 2802 & $100.0 \%$ & $0.77[0.61,0.9$ \\
\hline Total events & 139 & & 222 & & & \\
\hline
\end{tabular}

Heterogeneity: $\mathrm{Chi}^{2}=10.36, \mathrm{df}=12(\mathrm{P}=0.58) ; \mathrm{l}^{2}=0 \%$

Test for overall effect: $Z=2.18(P=0.03)$

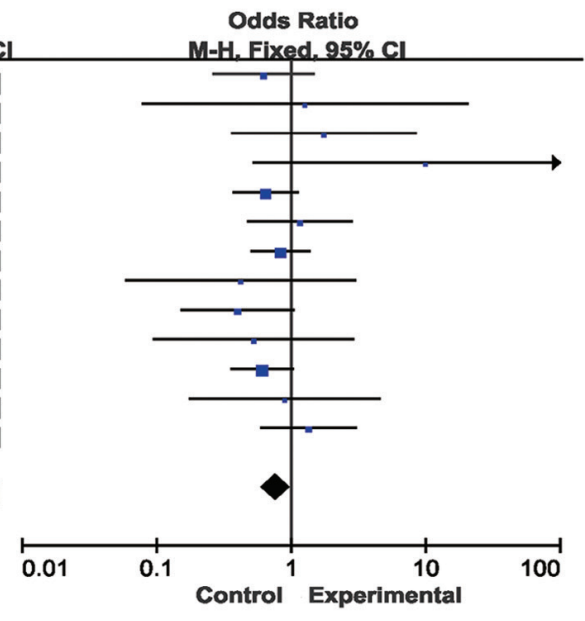

B

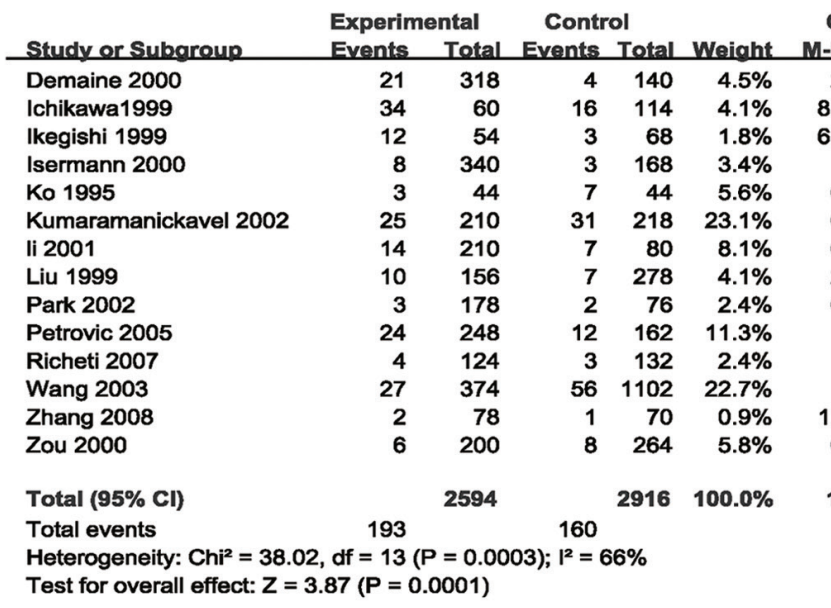

Odds Ratio

Odds Ratio

ixed. $95 \%$ C

$2.40[0.81,7.14]$

$8.01[3.84,16.70]$

$6.19[1.65,23.25]$

$1.33[0.35,5.06]$

$0.39[0.09,1.61]$

$0.82[0.46,1.43]$

$0.74[0.29,1.92]$

$2.65[0.99,7.11]$

$0.63[0.10,3.87]$

$1.34[0.65,2.76]$

$1.43[0.31,6.54]$

$1.45[0.90,2.34]$

$1.82[0.16,20.47]$

$0.99[0.34,2.90]$

$1.57[1.25,1.98]$

Test for overall effect: $Z=3.87(P=0.0001)$

C

\begin{tabular}{|c|c|c|c|c|c|c|}
\hline \multirow[b]{2}{*}{ Study or Subgroup } & \multicolumn{2}{|c|}{ Experimental } & \multirow{2}{*}{\multicolumn{2}{|c|}{$\begin{array}{l}\text { Control } \\
\text { Events Tot }\end{array}$}} & \multirow{2}{*}{ Weight } & \multirow{2}{*}{$\begin{array}{c}\text { Odds Ratio } \\
\text { M-H,Fixed, } 95 \% \text { C }\end{array}$} \\
\hline & & Total & & & & \\
\hline Demaine 2000 & 1 & 318 & 2 & 140 & $3.2 \%$ & $0.22[0.02,2.42]$ \\
\hline Ikegishi 1999 & 3 & 54 & 0 & 68 & $0.5 \%$ & $9.31[0.47,184.25]$ \\
\hline Isermann 2000 & 3 & 340 & 1 & 168 & $1.6 \%$ & $1.49[0.15,14.40]$ \\
\hline Kao 1999 & 6 & 134 & 17 & 194 & $15.5 \%$ & $0.49[0.19,1.27]$ \\
\hline Kumaramanickavel 2002 & 17 & 210 & 10 & 218 & $10.5 \%$ & $1.83[0.82,4.10]$ \\
\hline li 2001 & 4 & 210 & 0 & 80 & $0.8 \%$ & $3.51[0.19,65.91]$ \\
\hline Liu 1999 & 13 & 156 & 37 & 278 & $28.5 \%$ & $0.59[0.30,1.15]$ \\
\hline Petrovic 2005 & 2 & 248 & 2 & 162 & $2.8 \%$ & $0.65[0.09,4.66]$ \\
\hline Richeti 2007 & 1 & 124 & 2 & 132 & $2.2 \%$ & $0.53[0.05,5.90]$ \\
\hline Wang 2003 & 9 & 374 & 52 & 1102 & $30.1 \%$ & $0.50[0.24,1.02]$ \\
\hline Zhang 2008 & 1 & 78 & 1 & 70 & $1.2 \%$ & $0.90[0.05,14.60]$ \\
\hline Zou 2000 & 3 & 200 & 3 & 264 & $3.0 \%$ & $1.32[0.26,6.63]$ \\
\hline Total $(95 \% \mathrm{Cl})$ & & 2446 & & 2876 & $100.0 \%$ & $0.77[0.56,1.07]$ \\
\hline
\end{tabular}

Total events

63 127

Heterogeneity: $\mathrm{Chi}^{2}=13.00, \mathrm{df}=11(P=0.29) ; \mathrm{l}^{2}=15 \%$

Test for overall effect: $Z=1.56(P=0.12)$

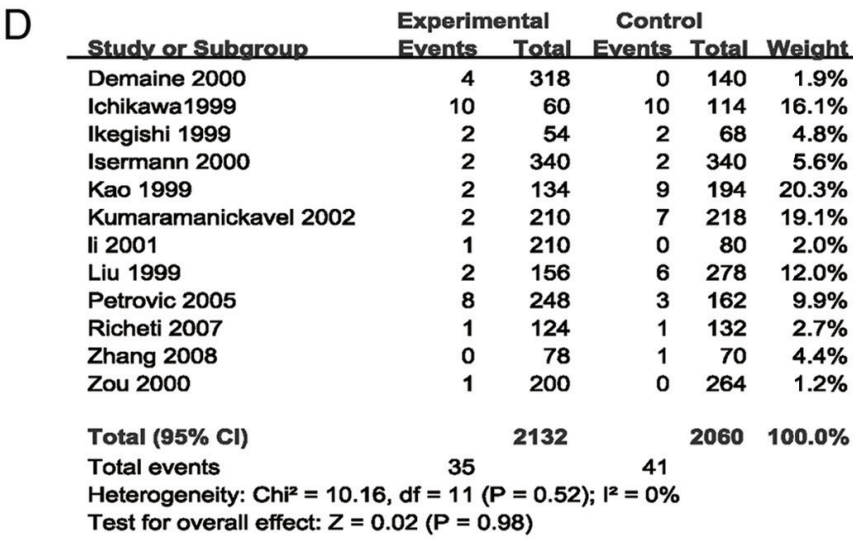

Odds Ratio
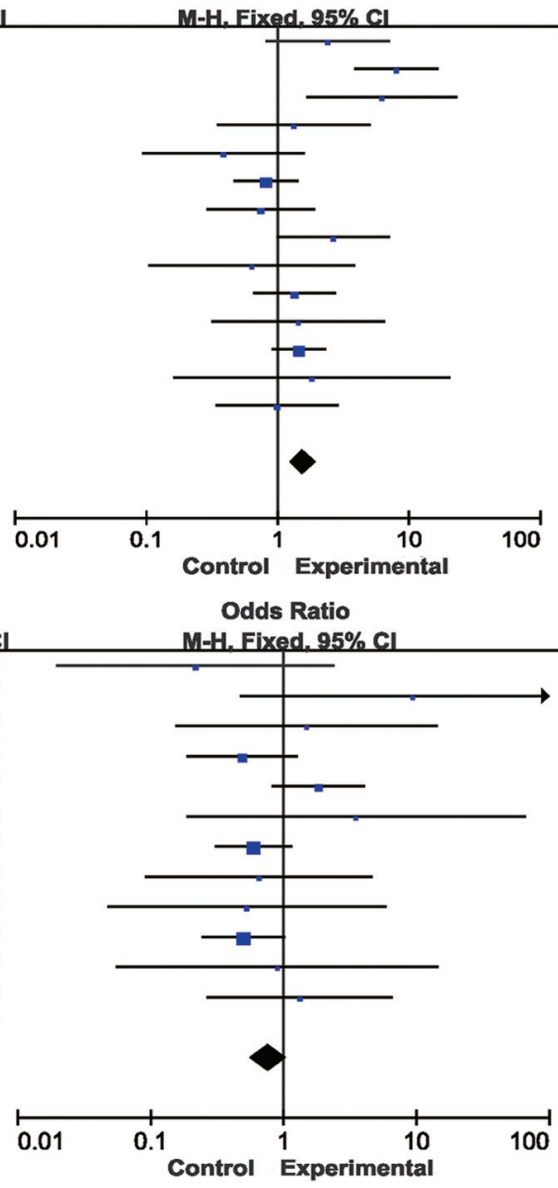

CI M-H, Fixed, $95 \%$ Cl 
A

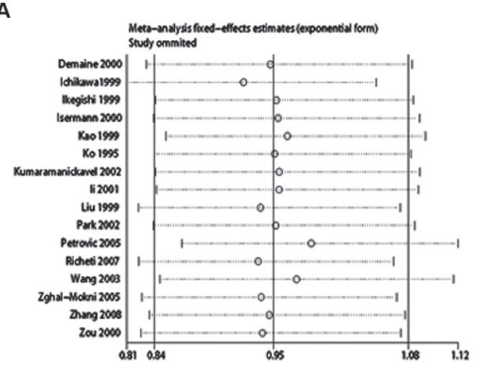

D

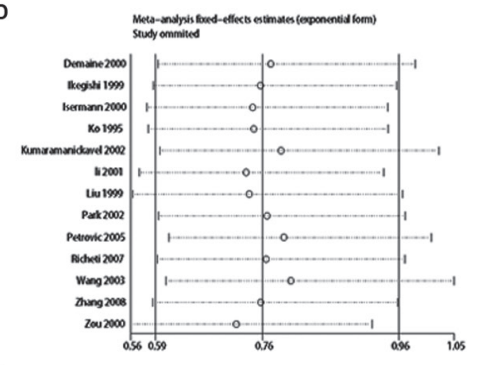

G

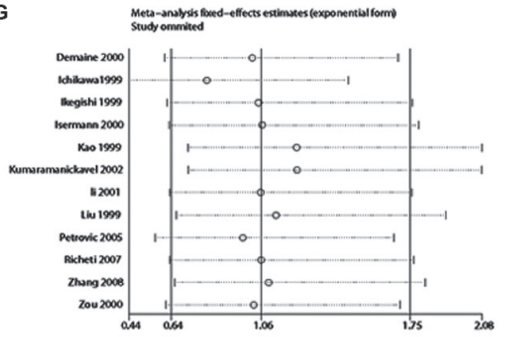

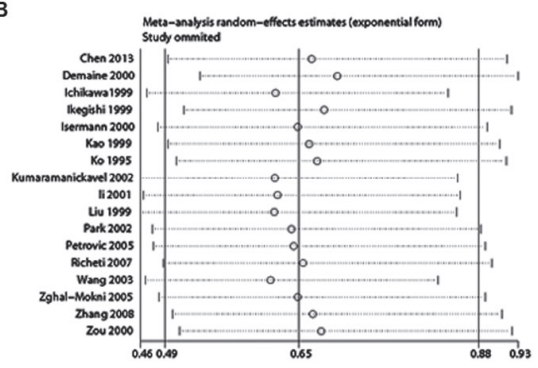

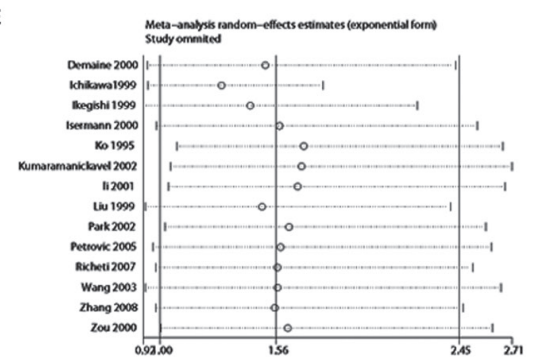

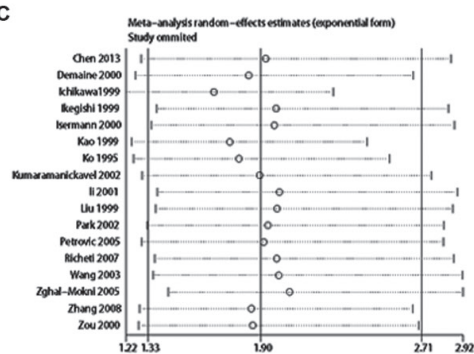

F

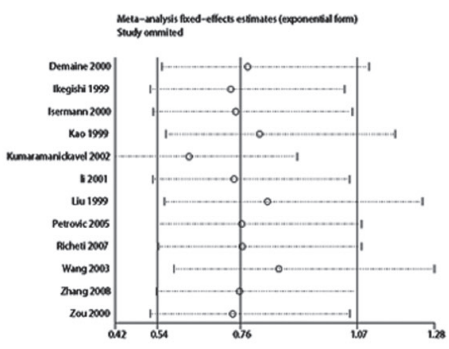

Figure 4. Sensitive analysis was performed by omitting data one study at a time to assess the influence of each study on the stability of the results regarding aldose reductase (CA)n. (A) Z; (B) Z+2; (C) Z-2; (D) Z+4; (E) Z-4; (F) Z+6; (G) Z-6. M-H, Mantel-Haentzel; df, degrees of freedom. On the X-axis, the brackets represent mean the pooled odds ratios whereas the vertical lines represent the $95 \%$ confidence intervals.

CI: 0.49-0.88, P=0.004; Fig. 2B). However, the Z-2 allele was significantly associated with an increased risk of $\mathrm{DR}(\mathrm{OR}=1.90$, 95\% CI: 1.33-2.71, P=0.0004; Table II, Fig. 2C). Significant associations were also detected between the $\mathrm{Z}+4(\mathrm{OR}=0.77$; 95\% CI, 0.61-0.97, $\mathrm{P}=0.03$; Fig. 3A) and $\mathrm{Z}-4(\mathrm{OR}=1.57$; $95 \%$ CI, 1.25-1.98; $P=0.0001$; Fig. 3B) alleles and the risk for DR. However, no association was detected between the $\mathrm{Z}, \mathrm{Z}+6$ or Z-6 alleles and the risk of DR ( $>>0.05$; Table II; Figs. 2A, $3 \mathrm{C}$ and $\mathrm{D}$, respectively). Stratification analyses based on ethnicity were then performed. The results indicated that the Z-2 allele was significantly associated with $\mathrm{DR}$ in Asian $(\mathrm{OR}=1.82$, 95\% CI: $1.16-2.86, \mathrm{P}=0.009)$ and Caucasian $(\mathrm{OR}=2.08,95 \%$ CI: $1.14-3.79, \mathrm{P}=0.02$ ) populations. $\mathrm{Z}+2$ was significantly associated with DR in Caucasian individuals $(\mathrm{OR}=0.50,95 \%$ CI: 0.34-0.73, $\mathrm{P}=0.0004)$, but not in Asian patients $(\mathrm{P}=0.07)$. Furthermore, Z-4 was significantly associated with DR in Asian populations $(\mathrm{OR}=1.57,95 \% \mathrm{CI}: 1.22-2.03, \mathrm{P}=0.0005)$, but not in Caucasian individuals $(\mathrm{P}=0.09)$. In addition, the $\mathrm{Z}+4$ allele was not significantly associated with DR in Asians or Caucasians $(\mathrm{P}>0.05)$. Stratification analyses based on the type of DM (T1D and T2D) were also performed. The results revealed that the Z-2 allele was associated with the risk of DR in patients with T1D $(\mathrm{OR}=3.42$, 95\% CI: 1.46-8.04, $\mathrm{P}=0.005)$ and $\mathrm{T} 2 \mathrm{D}(\mathrm{OR}=1.66$, 95\% CI: $1.05-2.63, \mathrm{P}=0.03)$. The $\mathrm{Z}+2$ allele was associated with the risk of DR in patients with $\mathrm{T} 1 \mathrm{D}(\mathrm{OR}=0.39,95 \% \mathrm{CI}$ : 0.27-0.57, $\mathrm{P}<0.00001)$, but not in patients with T2D $(\mathrm{P}>0.05)$. Furthermore, the $\mathrm{Z}+4(\mathrm{OR}=0.74 ; 95 \% \mathrm{CI}, 0.57-0.96 ; \mathrm{P}=0.02)$ and $\mathrm{Z}-4(\mathrm{OR}=1.62 ; 95 \% \mathrm{CI}, 1.27-2.08 ; \mathrm{P}=0.0001)$ alleles were associated with the risk of DR in patients with T1D, but not in patients with T2D ( $>>0.05$; Table II).

Heterogeneity. Statistically significant heterogeneity across studies was observed when analyzing the $\mathrm{Z}+2\left(\mathrm{I}^{2}=75 \%\right.$; $\mathrm{P}<0.00001), \mathrm{Z}-2\left(\mathrm{I}^{2}=84 \% ; \mathrm{P}<0.00001\right)$ and $\mathrm{Z}-4 \quad\left(\mathrm{I}^{2}=66 \%\right.$; $\mathrm{P}=0.0003$ ) alleles (Table II). Significant heterogeneity regarding Z+2 was primarily identified in the studies by Zou et al (37), Wang et al (38), Liu et al (25), Demaine et al (39), Li et al (34) and Ichikawa et al (40). Removal of these studies from the meta-analysis resulted in $40 \%(\mathrm{P}=0.08)$ heterogeneity. Significant heterogeneity regarding Z-2 was primarily present in the studies by Kao et al (24), Ko et al (29), Demaine et al (39), Zghal-Mokni et al (26), and Ichikawa et al (40). Removal of these studies from the meta-analysis resulted in $36 \%(\mathrm{P}=0.10)$ heterogeneity. Furthermore, the significant heterogeneity in Z-4 was mainly due to the study by Ichikawa et al (40); upon removal of this study from the meta-analysis, heterogeneity was reduced to $27 \%(\mathrm{P}=0.17)$ (Table $\mathrm{SII})$. In the subgroup analysis, significant heterogeneity across studies was identified regarding the Z+2, Z-2 and Z-4 alleles of Asian patients with T2D (Table II).

Sensitivity analysis and publication bias. In the sensitivity analysis, the influence of a single study on the overall risk estimate was determined by removing one article at a time. The results revealed that the ORs were not significantly altered in each genotype (Fig. 4). Begg's funnel plots and Egger's test were performed to assess publication bias. Some outliers were 
Table III. Egger's linear regression test for funnel plot asymmetries of (AC)n in the aldose reductase gene.

\begin{tabular}{lcr}
\hline Allele & P-value & $95 \%$ CI \\
\hline Z & 0.281 & $-0.8225458-2.62835$ \\
Z+2 & 0.084 & $-4.256574-0.3006727$ \\
Z-2 & 0.319 & $-1.63998-4.707237$ \\
Z+4 & 0.267 & $-0.5488476-1.791998$ \\
Z-4 & 0.967 & $-2.481549-2.578416$ \\
Z+6 & 0.340 & $-0.7528741-1.981472$ \\
Z-6 & 0.658 & $-2.021688-1.334716$ \\
\hline
\end{tabular}
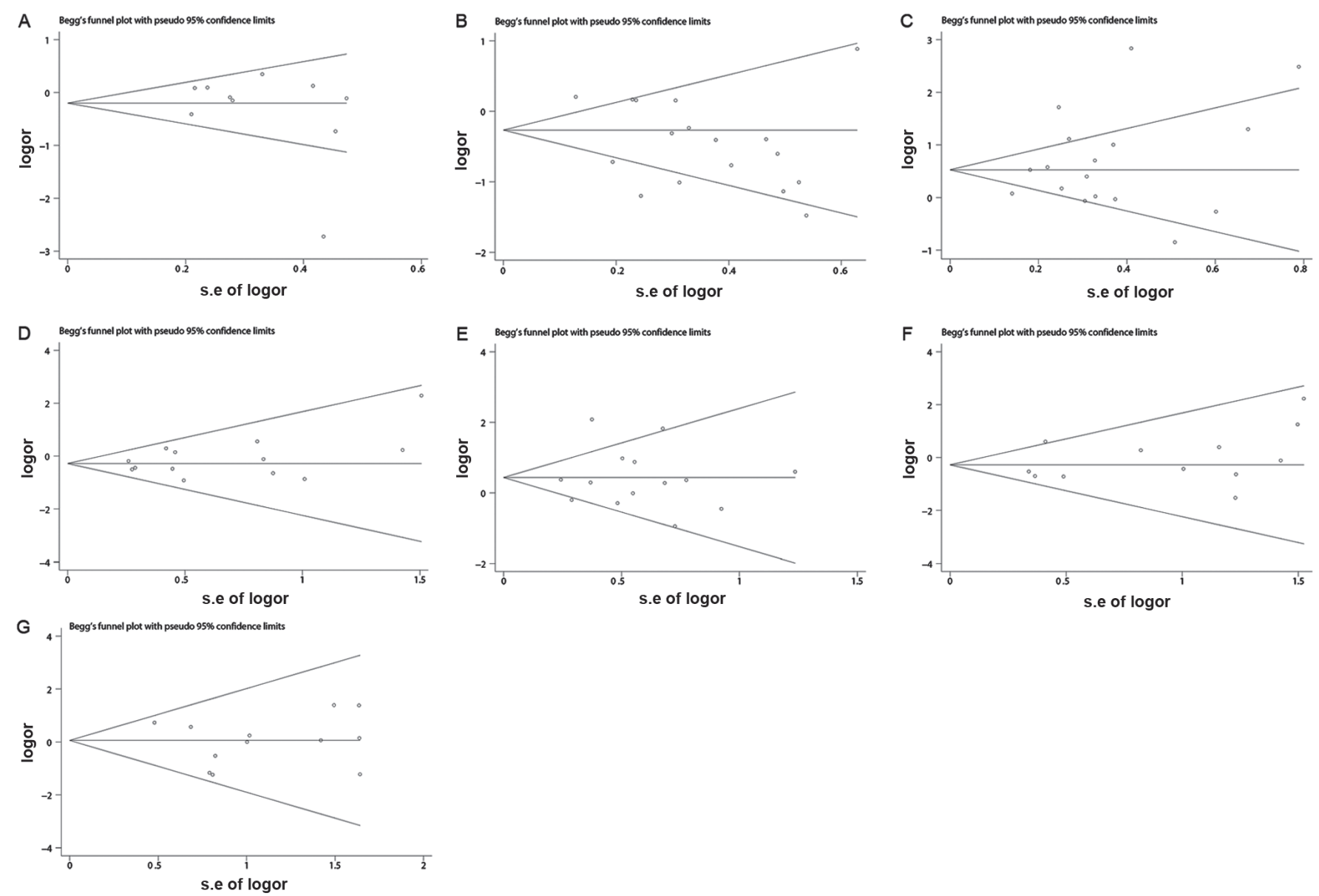

Figure 5. Publication bias of studies on aldose reductase (CA)n were tested by Begg's funnel plots. (A) Z; (B) Z+2; (C) Z-2; (D) Z+4; (E) Z-4; (F) Z+6; (G) Z-6. s.e., standard error; logor, log of odds ratio.

observed on the Begg's funnels plots, which may be due to the missed researches including articles with negative results and the small sample sizes of the studies. However, the results of Egger's test demonstrated that $\mathrm{P}>0.05$, which indicated the missed researches and the small sample sizes studies had no effects on the results. Therefore, the results indicated that there was no publication bias for the comparison of $Z, Z+2, Z-2$, Z+4, Z-4, Z+6 and Z-6 (Table III and Fig. 5).

\section{Discussion}

ALR is an NADPH-dependent enzyme that exhibits glucose-reducing activity (44). Elevated glucose levels may enhance ALR activity in the case of a hyperglycaemic event, which then increases the flux of glucose through the polyol pathway (45). This pathway has been revealed to serve an important role in diabetic complications, including nephropathy and retinopathy. Furthermore, significantly elevated ALR mRNA and protein levels have been detected in the peripheral blood monocytes of patients with DR (46). Therefore, inhibition of ALR expression may offer a therapeutic strategy for patients suffering from DR.

Recently, two common variants in the ALR gene, including a (CA)n dinucleotide repeat microsatellite and a 106C/T polymorphism, have been examined for their genetic association with DR in several populations $(36,38)$. The $(\mathrm{CA}) \mathrm{n}$ variant, located $2.1 \mathrm{~kb}$ 
upstream of the transcription initiation site of ALR, may alter the secondary structure of DNA (47) or RNA (48), consequently affecting splicing and the generation of non-coding RNA. Multiple alleles have been identified for the (CA)n variation, including Z, Z+2, Z-2, Z+4, Z-4, Z+6, Z-6, Z+8, Z-8, Z+10 and $\mathrm{Z}-10 . \mathrm{Z}, \mathrm{Z}+2$ and $\mathrm{Z}-2$ were the most common alleles identified as (CA)n variations. Furthermore, the Z-2 allele has been reported to be linked to increased expression of the ALR gene in the peripheral mononuclear cells of patients with diabetes or hyperglycaemia (49). In vitro gene reporter assays have revealed that the susceptibility polymorphism Z-2 increases transcriptional activity (49). In addition, the Z-2 allele has been associated with the susceptibility to DR (24). Other studies have also indicated that the $\mathrm{Z}+2$ allele serves a protective role against DR $(24,26,29)$. However, the results indicating the association between the Z-2 or Z+2 and DR were inconsistent and inconclusive. Among the 17 studies included in the present analysis, only $5(29,36,37,39,41)$ reported significant associations between $\mathrm{Z}+2$ and $\mathrm{DR}$, and the 12 remaining studies indicated negative results. In addition, regarding Z-2, 7 studies reported a significant association with DR $(24,29,30,36,37,39,40,42)$. However, the 10 remaining studies indicated no association between Z-2 and DR. The meta-analysis of the present study demonstrated that the Z-2 allele is likely to be a genetic risk factor $(O R=1.90)$, while the $Z+2$ may exert a protective effect to reduce the susceptibility to $\mathrm{DR}(\mathrm{OR}=0.65)$. However, a certain heterogeneity regarding Z+2 and Z-2 alleles was identified among the results of individual studies.

To determine the role of the genetic background and types of DM in DR, a subgroup analysis based on ethnicity and type of DM was performed in the present study. Subgroup analysis with stratification by ethnicity revealed that $\mathrm{Z}+2$ exerted protective effects for Caucasian patients with DR only. Furthermore, Z-2 was demonstrated to be a risk factor for DR in Asian as well as Caucasian populations. These inconsistent results in different populations may indicate the important role of the genetic background in the pathogenesis of DR (50-53). In addition, subgroup analysis with stratification by type of DM revealed that Z-2 was associated with DR in T1D and T2D. Furthermore, Z+2 was associated with DR in T1D, but not in T2D. The prevalence of DR was higher in patients with T1D, with sight-threatening retinopathy reported to be up to $2.5 \mathrm{x}$ more common than in those with T2D (54). However, despite including a larger number of patients with T2D, the meta-analysis of the present study only demonstrated a slight association between Z-2 and DR in T2D. This may indicate the importance of a larger sample size to provide a more accurate evaluation of the association between gene polymorphisms and disease susceptibility.

A significant association between Z+4 or Z-4 and DR was determined in the present meta-analysis. Based on a larger number of patients, the $\mathrm{Z}+4$ allele was determined to be a protective factor for DR, whereas the Z-4 allele was determined to be a risk factor for DR. However, none of the studies included detected any significant associations between $\mathrm{Z}+4$ and DR. Furthermore, only one study reported a significant association between Z-4 and DR (41). These results may indicate the importance of larger sample sizes to provide a more accurate evaluation of the genetic association and increased calculation power in the combined analysis. Subgroup analysis based on ethnicity and type of DM revealed that Z-4 may be a risk factor for DR in Asian populations, but not in Caucasians. In addition, Z+4 and Z-4 were only determined to be associated with DR in patients with T2D. To the best of our knowledge, the present study is the first to identify a significant association between Z+4 or Z-4 and the susceptibility for DR by performing a meta-analysis. However, to fully confirm these genetic associations, larger numbers of case-control studies with more patients are necessary.

The present meta-analysis had various limitations. First, the sample size in the present meta-analysis was relatively small. Although 17 studies with 1,575 cases and 1,741 controls were included, the sample size in the subgroup analysis, particularly in the Caucasian and T1D subgroups, was insufficient. Furthermore, only the genetic association between alleles of the (CA)n variation and DR were assessed. No data on the genotype and haplotype were provided. In addition, multiple factors, including genetic and environmental factors, or the interaction between the two factors and other unknown risk factors, were not considered in the pathogenesis of DR. Furthermore, the studies included in the present meta-analysis had been performed in either Asian or Caucasian populations, but not in any subjects of other ethnicities. To more precisely assess the association between (CA)n polymorphisms and DR, analysis of multiple populations is necessary. Finally, the information on the cases was relatively limited, and the present analysis did not assess the approach (or medication) to control glucose due to lack of data in the individual studies.

In conclusion, the $\mathrm{Z}+2$ allele may be a protective factor for DR in Caucasian patients with T1D. Furthermore, $Z+4$ may be a protective factor for DR in patients with T2D. However, Z-2 may be a risk factor for DR in all subgroups and Z-4 may be a risk factor for DR in Asian patients with T2D.

\section{Acknowledgements}

Not applicable.

\section{Funding}

The current study was funded by the Youth Foundation of the Education Department of Hunan (grant no. 17B035) and the Foundation of the Education Department of Hunan (grant no. 18C1186).

\section{Availability of data and materials}

The datasets used and/or analyzed during the current study are available from the corresponding author on reasonable request.

\section{Authors' contributions}

WSM and YHB participated in data curation, methodology, software and validation. YX participated in project administration and the acquisition of funding. WSM wrote the original manuscript draft. YX was involved with the conception and design of the current study and revising the manuscript critically for important intellectual content. YX and YHB reviewed and edited the manuscript.

\section{Ethics approval and consent to participate}

Not applicable. 


\section{Patient consent for publication}

Not applicable.

\section{Competing interests}

The authors declare that they have no competing interests.

\section{References}

1. Ola MS, Nawaz MI, Siddiquei MM, Al-Amro S and Abu El-Asrar AM: Recent advances in understanding the biochemical and molecular mechanism of diabetic retinopathy. J Diabetes Complications 26: 56-64, 2012.

2. Chang YC and Wu WC: Dyslipidemia and diabetic retinopathy. Rev Diabet Stud 10: 121-132, 2012.

3. Tuuminen R, Haukka J and Loukovaara S: Poor glycemic control associates with high intravitreal angiopoietin-2 levels in patients with diabetic retinopathy. Acta Ophthalmologica 93: e515-e516, 2015.

4. Grassi MA, Tikhomirov A, Ramalingam S, Below JE, Cox NJ and Nicolae DL: Genome-wide meta-analysis for severe diabetic retinopathy. Hum Mol Genet 20: 2472-2481, 2011.

5. Warpeha KM and Chakravarthy U: Molecular genetics of microvascular disease in diabetic retinopathy. Eye (Lond) 17: 305-311, 2003.

6. Gonzalez-Salinas R, Garcia-Gutierrez MC, Garcia-Aguirre G Morales-Canton V, Velez-Montoya R, Soberon-Ventura VR, Gonzalez V,Lechuga R, Garcia-Solis P, Garcia-Gutierrez DG, et al: Evaluation of VEGF gene polymorphisms and proliferative diabetic retinopathy in Mexican population. Int J Ophthalmol 10 135-139, 2017.

7. Wang W, He M and Huang W: Association of monocyte chemoattractant protein-1 gene $2518 \mathrm{~A} / \mathrm{G}$ polymorphism with diabetic retinopathy in type 2 diabetes mellitus: A meta-analysis Diabetes Res Clin Pract 120: 40-46, 2016.

8. Zhang Y, Xia W, Lu P and Yuan HJ: The association between VDR gene polymorphisms and diabetic retinopathy susceptibility: A systematic review and meta-analysis. Biomed Res Int 2016: 5305282, 2016.

9. Li GY, Li ZB, Li F, Dong LP, Tang L, Xiang J, Li JM and Bao MH Meta-analysis on the association of ALDH 2 polymorphisms and type 2 diabetic mellitus, diabetic retinopathy. Int J Environ Res Public Health 14: pii: E165, 2017.

10. Fujisawa T, Ikegami H, Kawaguchi Y, Shintani M, Kawabata Y, Ono M, Nishino M, Ogihara T, Okamoto N and FukudaM: Genetic susceptibility to diabetic retinopathy: CA repeat polymorphism of the aldose reductase gene. Folia Jap Ophthalmol Clin 52: 128-130, 2001.

11. Abhary S, Burdon KP, Laurie KJ, Thorpe S, Landers J, Goold L, Lake S, Petrovsky N and Craig JE: Aldose reductase gene polymorphisms and diabetic retinopathy susceptibility. Diabetes Care 33: 1834-1836, 2010.

12. Crespo I, Giménez-Dejoz J, Porté S, Cousido-Siah A, Mitschler A, Podjarny A, Pratsinis H, Kletsas D, Parés X, Ruiz FX, et al: Design, synthesis, structure-activity relationships and X-ray structural studies of novel 1-oxopyrimido[4,5-c] quinoline-2-acetic acid derivatives as selective and potent inhibitors of human aldose reductase. Eur J Med Chem 152: $160-174,2018$

13. Radha V, Rema M and Mohan V: Genes and diabetic retinopathy. Indian J Ophthalmol 50: 5-11, 2002

14. Graham A, Brown L, Hedge PJ, Gammack AJ and Markham AF: Structure of the human aldose reductase gene. J Biol Chem 266: 6872-6877, 1991.

15. Li YY, Wang H, Yang XX, Geng HY, Gong G and Lu XZ: AR C-106T gene polymorphism and diabetic nephropathy in the Eastern Asians with T2DM: A meta-analysis including 2120 subjects. Diabetes Res Clin Pract 130: 244-251, 2017.

16. Gupta B and Singh SK: Association of aldose reductase gene polymorphism (C-106T) in susceptibility of diabetic peripheral neuropathy among north Indian population. J Diabetes Complications 31: 1085-1089, 2017.

17. Abhary S, Hewitt AW, Burdon KP and Craig JE: A systematic meta-analysis of genetic association studies for diabetic retinopathy. Diabetes 58: 2137-2147, 2009.
18. Olmos P, Bastías MJ, Vollrath V, Toro L, Trincado A, Salinas P, Claro JC, López JM, Acosta AM, Miquel JF and Castro J: C(-106) $\mathrm{T}$ polymorphism of the aldose reductase gene and the progression rate of diabetic retinopathy. Diabetes Res Clin Pract 74: $175-182,2006$

19. Zhou M, Zhang P, Xu X and Sun Z: The relationship between aldose reductase $\mathrm{C} 106 \mathrm{~T}$ polymorphism and diabetic retinopathy: An updated meta-analysis. Invest Ophthalmol Vis Sci 56 : 2279-2289, 2015

20. Song ZD, Tao Y, Han N and Wu YZ: Association of the aldose reductase-106TT genotype with increased risk for diabetic retinopathy in the Chinese han population: An updated meta-analysis. Curr Eye Res 41: 1087-1091, 2015.

21. Ng DP, Conn J, Chung SS and Larkins RG: Aldose reductase (AC)n microsatellite polymorphism and diabetic microvascular complications in Caucasian Type 1 diabtes mellitus. Diabetes Res Clin Pract 52: 21-27, 2001.

22. dos Santos KG, Canani LH, Gross JL, Tschiedel B, Souto KE and Roisenberg I: The-106CC genotype of the aldose reductase gene is associated with an increased risk of proliferative diabetic retinopathy in Caucasian-Brazilians with type 2 diabetes. Mol Genet Metab 88: 280-284, 2006.

23. Heesom AE, Hibberd ML, Millward A and Demaine AG: Polymorphism in the 5 '-end of the aldose reductase gene is strongly associated with the development of diabetic nephropathy in type I diabetes. Diabetes 46: 287-291, 1997.

24. Kao YL, Donaghue K, Chan A, Knight J and Silink M: An aldose reductase intragenic polymorphism associated with diabetic retinopathy. Diabetes Res Clin Pract 46: 155-160, 1999.

25. Liu L, Xiang K and Zheng T: A study of association between polymorphism of aldose reductase gene and diabetic microangiopathy. Chin J Endocrinol Metab 15: 263-266, 1999.

26. Zghal-Mokni I, Arfa I, Elloumi-Zghal H, Abid A, Amrouche-Rached C, Kaabi B, Chakroun S, Blousa-Chabchoub S, Gaïgi S, Ayed S, et al: Association study between diabetic retinopathy and aldose reductase gene polymorphism in Tunisians. J Fr Ophtalmol 28: 386-390, 2005 (In French).

27. Richeti F, Noronha RM, Waetge RT, de Vasconcellos JP, de Souza OF, Kneipp B, Assis N, Rocha MN, Calliari LE, Longui CA, et al: Evaluation of $\mathrm{AC}(\mathrm{n})$ and $\mathrm{C}(-106) \mathrm{T}$ polymorphisms of the aldose reductase gene in Brazilian patients with DM1 and susceptibility to diabetic retinopathy. Mol Vis 13: 740-745, 2007.

28. Park HK, Ahn CW, Lee GT, Kim SJ, Song YD, Lim SK, Kim KR, Huh KB and Lee HC: (AC)(n) polymorphism of aldose reductase gene and diabetic microvascular complications in type 2 diabetes mellitus. Diabetes Res Clin Pract 55: 151-157, 2002.

29. Ko BC, Lam KS, Wat NM and Chung SS: An (A-C)n dinucleotide repeat polymorphic marker at the $5^{\prime}$ end of the aldose reductase gene is associated with early-onset diabetic retinopathy in NIDDM patients. Diabetes 44: 727-732, 1995.

30. Petrovic MG, Peterlin B, Hawlina M and Petrovic D: Aldose reductase $(\mathrm{AC}) \mathrm{n}$ gene polymorphism and susceptibility to diabetic retinopathy in type 2 diabetes in Caucasians. J Diabetes Complications 19: 70-73, 2005

31. Higgins J and Green S, (eds): Cochrane handbook for systematic reviews of interventions, version 5.1.0 [updated March 2011]. The Cochrane Collaboration, 2011.

32. Boccia S: PRISMA: An attempt to improve standards for reporting systematic review and meta-analysis. Epidemiol Biostatist Public Health 6: E382, 2009.

33. Wells GA, Shea BJ, O'Connell D, Robertson J, Peterson J, Welch V, Losos M and Tugwell P: The newcastle-ottawa scale (NOS) for assessing the quality of nonrandomized studies in meta-analysis. Appl Eng Agric 18: 727-734, 2014.

34. Li QJ, Xie P, Zeng WM and Song HP: Correlation between (AC) $\mathrm{n}$ polymorphism of the aldose reductase gene and retinopathy in type 2 diabetes mellitus. Chin J Endocrinol Metab 17: 367-368, 2001.

35. Zhang JH, Wang HY and Li SY: Correlation between polymorphism of the aldose reductase gene and retinopathy in type 2 diabetes mellitus. J Shandong Univ 46: 399-406, 2008.

36. Chen S, Liu CS and Wang XJ: The correlation study between the two gene polymorphism of aldose reductase gene 5 'end and diabetic retinopathy. China Mod Med 20: 13-15, 2013

37. Zou X and Lu J: Study on the relationship between the polymorphism of (ac)n in the 5'-end of the ar gene and the susceptibility of microangopathy in type 2 diabetes mellitus. Med J Chin Peoples Liberat Army 25: 353-356, 2000. 
38. Wang Y, Ng MC, Lee SC, So WY, Tong PC, Cockram CS Critchley JA and Chan JC: Phenotypic heterogeneity and associations of two aldose reductase gene polymorphisms with nephropathy and retinopathy in type 2 diabetes. Diabetes Care 26: 2410-2415, 2003.

39. Demaine A, Cross D and Millward A: Polymorphisms of the aldose reductase gene and susceptibility to retinopathy in type 1 diabetes mellitus. Invest Ophthalmol Vis Sci 41: 4064-4068, 2000.

40. Ichikawa F, Yamada K, Ishiyama-Shigemoto S, Yuan X and Nonaka K: Association of an (A-C)n dinucleotide repeat polymorphic marker at the 5'-region of the aldose reductase gene with retinopathy but not with nephropathy or neuropathy in Japanese patients with Type 2 diabetes mellitus. Diabet Med 16: 744-748, 1999.

41. Ikegishi Y, Tawata M, Aida K and Onaya T: Z-4 allele upstream of the aldose reductase gene is associated with proliferative retinopathy in Japanese patients with NIDDM, and elevated luciferase gene transcription in vitro. Life Sci 65: 2061-2070, 1999.

42. Kumaramanickavel G, Sripriya S, Ramprasad VL, Upadyay NK, Paul PG and Tarun S: Z-aldose reductase allele and diabetic retinopathy in India. Ophthalmic Genet 24: 41-48, 2003.

43. Isermann B, Susanne Schmidt, Bierhaus A, Schiekofer S, Borcea V, Ziegler R, Nawroth PP and Ritz E: (CA)(n) dinucleotide repeat polymorphism at the 5'-end of the aldose reductase gene is not associated with microangiopathy in Caucasians, with long-term diabetes mellitus 1 . Nephrol Dial Transplant 15 : 918-920, 2000

44. Kaur N and Vanita V: Association of aldose reductase gene (AKR1B1) polymorphism with diabetic retinopathy. Diabetes Res Clin Pract 121: 41-48, 2016.

45. Petrash JM, Flath M, Sens D and Bylander J: Effects of osmotic stress and hyperglycemia on aldose reductase gene expression in human renal proximal tubule cells. Biochem Biophys Res Commun 187: 201-208, 1992.
46. Nishimura C, Saito T, Ito T, Omori Y and Tanimoto T: High levels of erythrocyte aldose reductase and diabetic retinopathy in NIDDM patients. Diabetologia 37: 328-330, 1994

47. Lu L, Risch E, Deng Q, Biglia N, Picardo E, Katsaros D and Yu H: An insulin-like growth factor-II intronic variant affects local DNA conformation and ovarian cancer survival. Carcinogenesis 34: 2024-2030, 2013.

48. Lu L, Katsaros D, Mayne ST, Risch HA, Benedetto C, Canuto EM and $\mathrm{Yu} \mathrm{H}$ : Functional study of risk loci of stem cell-associated gene lin-28B and associations with disease survival outcomes in epithelial ovarian cance. Carcinogenesis 33: 2119-2125, 2012.

49. Shah VO, Scavini M, Nikolic J, Sun Y, Vai S, Griffith JK, Dorin RI, Stidley C, Yacoub M, Vander Jagt DL, et al: Z-2 microsatellite allele is linked to increased expression of the aldose reductase gene in diabetic nephropathy. J Clin Endocrinol Metab 83: 2886-2891, 1998.

50. Donaghue KC, Margan SH, Chan AK, Holloway B, Silink M, Rangel $\mathrm{T}$ and Bennetts $\mathrm{B}$ : The association of aldose reductase gene (AKR1B1) polymorphisms with diabetic neuropathy in adolescents. Diabet Med 22: 1315-1320, 2005.

51. Liew G, Klein R and Wong TY: The role of genetics in susceptibility to diabetic retinopathy. Int Ophthalmol Clin 49: 35-52, 2009.

52. Cho H and Sobrin L: Genetics of diabetic retinopathy. Curr Diab Rep 14: 515, 2014.

53. Ju Z, Daichao W, Yan L and Tan SJ: Association of luteinizing hormone/choriogonadotropin receptor gene polymorphisms with polycystic ovary syndrome risk: A meta-analysis. Gynecol Endocrinol 35: 81-85, 2019.

54. Roy MS, Klein R, O'Colmain BJ, Klein BE, Moss SE and Kempen JH: The prevalence of diabetic retinopathy among adult type 1 diabetic persons in the United States. Arch Ophthalmol 122: 546-551, 2004. 